This item was submitted to Loughborough's Research Repository by the author.

Items in Figshare are protected by copyright, with all rights reserved, unless otherwise indicated.

\title{
What is a 'good' job? Modelling job quality for blue collar workers
}

\section{PLEASE CITE THE PUBLISHED VERSION}

http://dx.doi.org/10.1080/00140139.2016.1165870

\section{PUBLISHER}

(C) Informa UK

\section{VERSION}

AM (Accepted Manuscript)

\section{PUBLISHER STATEMENT}

This work is made available according to the conditions of the Creative Commons Attribution-NonCommercialNoDerivatives 4.0 International (CC BY-NC-ND 4.0) licence. Full details of this licence are available at: https://creativecommons.org/licenses/by-nc-nd/4.0/

\section{LICENCE}

CC BY-NC-ND 4.0

\section{REPOSITORY RECORD}

Jones, Wendy, Roger Haslam, and Cheryl Haslam. 2019. "What Is a 'good' Job? Modelling Job Quality for Blue Collar Workers". figshare. https://hdl.handle.net/2134/20986. 


\section{What is a 'good' job? Modelling job quality for blue collar workers}

Wendy Jones, School of Civil and Building Engineering, Loughborough University,

Loughborough, LE11 3TU, UK

w.jones2@lboro.ac.uk 01509226916 (corresponding author)

Roger Haslam, Loughborough Design School, Loughborough University, Loughborough, LE11 3TU, UK

r.a.haslam@lboro.ac.uk 01509223042

Cheryl Haslam, School of Sport, Exercise and Health Sciences, Loughborough University, Loughborough, LE11 3TU, UK

c.o.haslam@lboro.ac.uk 01509223086

The research was conducted at Loughborough Design School, Loughborough University 


\title{
What is a 'good' job? Modelling job quality for blue collar workers
}

\begin{abstract}
This paper proposes a model of job quality, developed from interviews with blue collar workers: bus drivers, manufacturing operatives and cleaners $(n=80)$. The model distinguishes between core features, important for almost all workers, and 'job fit' features, important to some but not others, or where individuals might have different preferences. Core job features found important for almost all interviewees included job security, personal safety, and having enough pay to meet their needs. 'Job fit' features included autonomy and the opportunity to form close relationships. These showed more variation between participants; priorities were influenced by family commitments, stage of life and personal preference. The resulting theoretical perspective indicates the features necessary for a job to be considered 'good' by the person doing it, whilst not adversely affecting their health. The model should have utility as a basis for measuring and improving job quality and the laudable goal of creating 'good jobs'.
\end{abstract}

\section{Keywords}

Job quality; good jobs; good work; health; bus drivers

\section{Practitioner summary}

Good work can contribute positively to health and wellbeing, but there is a lack of agreement regarding the concept of a 'good' job. A model of job quality has been constructed based on semi-structured worker interviews $(n=80)$. The model emphasises the need to take into account variation between individuals in their preferred work characteristics.

\section{Introduction}

The concept of the 'good job' or 'good work' is a broad one. It has been explored from philosophical standpoints (Schumacher 1979; Sennett 2008) and health based perspectives (Waddell and Burton 2006); it is of interest to employees and their trade unions (Johansson and Abrahamsson 2009) as well as to their employers (Coats and Lekhi 2008); and it has been considered within particular industries (Berthelsen et al. 2010; Jones et al 2014a), within a national context (Mussman 2009; Michenthaler 2006) and internationally (ILO 2006; WHO 2010). There is however no clear agreement of what a 'good' job is, nor consensus on how the term should be defined or used. For example, it could be described in terms of its 
components or characteristics, the different elements that combine to make it; thus a good job might be one which has high pay, interesting job content and good job security. Alternatively the focus might be on the outputs or outcomes of a particular job, whether work has a positive or negative impact on an individual's health or wellbeing. In this context a good job might be defined as one which has a positive impact on health. There is also a view postulated that a 'good job' cannot exist as a universal construct given the wide variation between individuals in their preferences and drivers (Cooke, Donaghey and Zeytinoglu 2013). Thus, the more important measure becomes the 'right' job, how well a job suits a particular individual.

This paper will proceed by exploring the job quality literature and the concept of a good job from these different perspectives. It will also explain why the consideration of job quality is an important area of study in ergonomics. It will then describe a study to explore the 'good' job from the perspective of workers and will use the findings to build on the literature and construct a preliminary model of job quality. Such a model can potentially be used as a yardstick against which jobs and industries can be measured, helping to drive an improvement in the quality of work offered, with potential benefits for employees, employers and society at large.

\section{Components and characteristics of jobs}

Job quality and the job characteristics which influence it is a theme widely discussed in the academic literature, with authors from different disciplinary perspectives focussing on a variety of attributes. For example, Gallie (2013) describes job quality within the sociological tradition as being underpinned by 'the intrinsic quality of work', considering factors such as skill, autonomy and job enrichment. Other authors have paid greater attention to extrinsic factors such as pay and security (Grzywacz and Dooley 2003); to the impact of psychosocial demands, exemplified by models such as Effort Reward Imbalance (Siegrist 1996) and Job Demands-Control (JD-C) (Karasek 1979; Karasek et al. 1981); or to developments of these which include the impact of relationships (Johnson and Hall 1988) or resources (Bakker, van Veldhoven and Xanthopoulou 2010). There are therefore a range of job features which have been recognised as contributing to job quality in some way. These can be combined to construct an overall picture of a good job, and indeed they have been (Bonnet, Figueiredo and Standing 2003; ILO 2006; Munoz de Bustillo et al 2011;Warr 2007a) but the exact content of the shortlist chosen is likely to be influenced by the backgrounds and perspectives of the author in each case.

\section{Individual preference}

A further difficulty of defining a good job in terms of characteristics such as pay, autonomy and relationships is that different individuals will have different preferences and priorities. The range of abilities, circumstances and personality types amongst the working population makes it inevitable (and generally fortuitous) that different people will favour different jobs (Edwards and Cooper 1990; Warr 2007a). In addition, individuals may change over time in terms of their priorities, their family commitments and their work capacity. These variances are widely accepted and accounted for in the literature - for example studies which consider the relationship between individual job factors and health commonly correct for differences between genders, age groups or socioeconomic background. However, when job characteristics are combined to create a single model or measure of job quality this variation 
is often ignored and a 'one size fits all' perspective is adopted. For example, a complex and comprehensive model of job quality by Munoz de Bustillo et al (2011a) scores jobs which involve evening or weekend working as being disadvantageous, even though there may be some individuals who prefer such work. Similar assumptions made by authors who have explored job quality widely across Europe discount the importance of matching the individual to the job (e.g. Jettinghoff and Houtman 2009; Leschke, Watt and Finn 2008; Wallace, Pichler and Hayes 2007). A consequence of this is that jobs may be identified as theoretically 'good' even though they do not suit those doing them. Kalleberg (2008) has highlighted the importance of matching individuals to jobs, identifying five types of mismatch - skills, location, time, earning, and work-family conflict. Individuals, he observes, trade off good matches in some dimensions to avoid mismatch in others with adverse impacts for individuals and organisations. Evaluating against a single measure of a good job may fail to reflect this: it ignores the personal nature of the construct and the extent to which it is influenced by individual experiences, life goals and by the standards of the community to which workers compare themselves (Cooke, Donaghey and Zeytinoglu 2013).

\section{Measuring job quality}

If it is accepted that, despite these challenges, there is a benefit in measuring the factors which influence job quality, additional difficulties arise when attempting to quantify these factors (see, for example, Jones et al 2014a). Many assessments such as the European Working Conditions Survey (EWCS), the British Household Panel Survey (BHPS) and the International Social Survey Programme (ISSP) use subjective measures, gathering data through the use of questionnaires and interviews. Such data reflect job quality from the particular perspective of individuals and are important, often being closely associated with outcome measures (Doef and Maes 1999). However, there are disadvantages to these methods, especially the influence which expectations have on responses. Thus those with low expectations often score poor quality jobs relatively highly (Schokkaert, Van Ootegem and Verhofstadt 2011); whilst those in relatively good jobs may score them poorly due to 'common indifference to what one already has' (Tangian 2009). These biases are particularly problematic if global subjective measures such as job satisfaction are used as a proxy for job quality. Despite arguments that such measures have 'a core of rationality' and are a useful way of enabling individuals to balance out the various aspects of their working lives (Rose 2003; Ritter and Anker 2002), they have been shown to vary relatively little between individuals, despite wide variation in terms of job features such as job security and pay. Neither do they vary greatly between disparate countries (Muñoz de Bustillo Llorente and Fernández Macías 2005).

\section{The relationship between work and health}

An alternate perspective on job quality is to consider the effects on those who do jobs, particularly in terms of the impact on health and wellbeing. There is substantial and longstanding evidence regarding the potential for work to adversely affect health. Ramazzini observed in 1713 the 'various and manifold ...harvest of diseases reaped by certain workers from their crafts and trades that they pursue' (Ramazzini, translated by Wright 1964). A similarly bleak contemporary picture sees over 2 million deaths worldwide directly attributable to work related accidents or ill-health (ILO 2013). A good job, therefore could be defined at its most basic level as one which does not cause harm to the health of those who 
undertake it. However, there is also an argument that good quality work can have a positive influence on health. This includes the contribution which purposeful activity and striving against adversity makes to happiness (Warr 2007b), the significance of social relationships (Cooke, Donaghey and Zeytinoglu 2013) and the health benefits of physical activity at work (Straker and Mathiassen 2009). A substantial literature review by Waddell and Burton (2006) confirmed the health benefits of employment (compared to unemployment) and more recent work by Sahlgren (2013) demonstrated net benefits of remaining in work compared to retirement. Such findings have influenced Government policy in the UK, for example, with measures designed to motivate those with health conditions and disabilities to engage in paid employment (Department for Work and Pensions / Department of Health 2008). With this perspective a good job would be one which had a positive impact on health rather than just not having adverse effects.

\section{An ergonomics approach to defining a good job}

The study of job quality in ergonomics has traditionally focussed on job design, considering job content, roles and tasks (Holman, Clegg and Waterson 2002), and seeking to improve effectiveness and productivity (Waterson 2011, Singleton 1972). However, there is also a concern for the impact of work, and an interest in the burden of workplace morbidity from poor quality work. Recent examples from the ergonomics literature consider how the incidence of work related musculoskeletal disorders might be influenced by job rotation (Leider et al 2015; Luger et al 2014) or psychosocial factors (Bao et al 2015). The study of good quality jobs and their beneficial effects for the worker in a wider sense is a reasonable extension of this. In addition, the study of good jobs can benefit from the systems perspective of ergonomics, accepting that workers, jobs and employers are influenced by factors within the wider environment (Dul et al 2012). The importance of individual variation, discussed above, is also an important concept in ergonomics. Finally, ergonomics has expertise in demonstrating the practical or financial benefits of interventions to organisations, which is important if employers are to be persuaded of the benefits of improving job quality.

\section{Study aims and methods}

The aim of this study was to examine if it is possible to model job quality in a way which reconciles the different perspectives found in the literature. Such a model would be one which could usefully support measurement and comparisons of job quality and thus drive its improvement; but would still take into account the interplay with individual preference. The study focussed on bus drivers, cleaners and manufacturing workers. These are all occupations where employees are not required to have high levels of formal education. The decision to use this narrow cohort was taken to reduce the extent of variation between interviewees and hence improve the focus on key issues when constructing a preliminary model. Nevertheless the selection of organisations ensured that there were still many differences between jobs, as the sample covered full time and part time roles, industries which employed predominantly either men or women, sedentary and active roles, and companies which had a reputation for offering 'good' or 'bad' jobs.

The study involved semi structured interviews with participants $(\mathrm{n}=80)$ as summarised below. They were drawn from five organisations, pseudonyms have been used to protect their identity. 
a) CleanCo - 20 participants (out of a workforce of 140) who were employed as cleaners of student accommodation in a higher educational establishment

b) ManCo -10 participants (out of 275) who were employed as production operatives in a multinational manufacturing organisation

c) LittleBus - 11 participants (out of 110) who were employed as drivers in a family run company which operated timetabled bus services and private coach hire

d) LittleCoach - 10 participants (out of 60) who were employed as drivers in a family run company which operated private coach hire

e) BigBus - 29 participants (out of 800) who were employed as drivers in a company operating timetabled bus services from several depots in and around a city centre.

Interviewees at three of the organisations were selected by line managers, based on availability at the time the researcher was scheduled to attend. At the other two (bus) companies, the researcher recruited interviewees directly by approaching drivers in the depot and asking if they would participate either then or at a mutually convenient time. In all cases, interviewees were recruited to cover a spread of ages and length of service; male and female; and different roles where applicable. Managers were asked not to select interviewees according to any other criteria (e.g.an expectation that someone would be a good or willing interviewee or have particularly positive or negative things to say). Interviews were conducted during paid work time; they were digitally recorded and subsequently transcribed. Typical interview duration was around 25 minutes.

The interview schedule drew on the literature and findings of a repertory grid study reported in Jones et al (2014b). It included open questions about the features interviewees associated with a 'good' job and also those which they associated with a job which was good for health. It also asked about factors which had influenced job choice. In addition, to allow comparison between companies, a series of closed questions was used: interviewees were asked to rate the importance of twelve features of job quality. These features had been identified from the literature, and were then refined through pilot testing. For each feature, respondents were asked how important it was to make a job a 'good' job for them (very important, quite important, not important). They were then asked to review the factors they had identified as 'very important' and decide which were most critical to make a job good, these (two to four items) were reclassified as 'most important'.

Qualitative data were imported into NVivo and evaluated using thematic analysis (Braun and Clarke 2006). Coding was both deductive, based on themes commonly used in the literature to define job quality such as pay, security, safety etc.; and inductive, using themes which were identified from the data. Responses to the closed questions were quantified to enable comparisons between the industries regarding the proportion who found each job feature to be important or not, and differences were tested for significance using a chi squared test on dichotomised data. Further details can be found in Jones et al (2014b).

\section{Key Findings}

Four important themes which emerged from the interviews related to:

- features of good quality work which were important to all, subsequently categorised as 'core features' of a good job;

- the variation between individuals beyond this in terms of how they identified a good job; 
- how interviewees chose particular jobs and the compromises they made in doing so; and

- the relationship between the concept of a 'good' job and a job which interviewees considered to be good for health.

These are discussed below, using quotes from a number of interviewees to illustrate the key points.

\section{Core features of job quality}

Figure 1 summarises the responses given to the closed interview questions about the perceived importance of particular features to make a job good. These show that the features safety and job security were of high importance to almost all employees in all three industries. This correlates with the literature which shows security to have a strong influence on both health and job satisfaction (Rose 2003; Clark 2005; Muñoz de Bustillo Llorente et al 2009). The perceived importance of safety to employees is rarely addressed in studies of job preference or satisfaction, but provision of safe working conditions is clearly important in order to minimise ill health or injury as well as to comply with legislative requirements (e.g. HSE 1974).
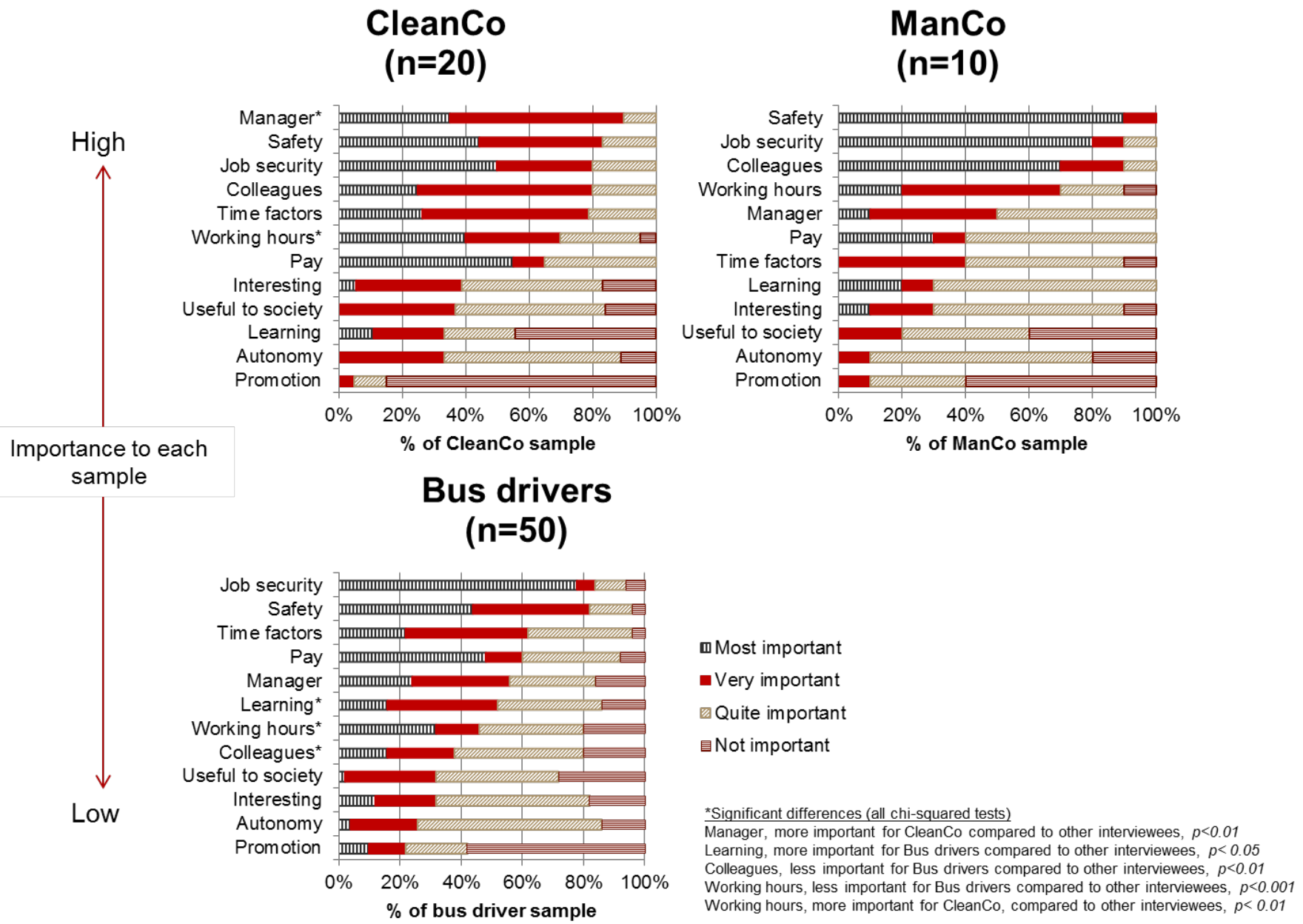

Figure 1 - Perceived importance of job features for the different interviewee samples 


\section{Variable features in job quality}

Figure 1 also illustrates that a number of features were more important to some interviewees than to others. There was variation between the employees from different industries. Having a good manager, for example, was considered very important by those interviewees who were employed as cleaners, but significantly less so by those working in other fields. This could reflect the differing roles of managers in the various industries and their impact on employees' experience of work . For example it was apparent from interviews that managers at CleanCo directly affected the day to day experiences of the cleaners - allocating duties, judging work quality and permitting rearrangement of working hours. In the other organisations, by comparison, work was allocated centrally and managers had a lower profile, with responsibilities which were seen as being limited to discipline and problem solving,

“as long as we know what we are making we don't need anyone to tell us... you go on the computer, it tells you exactly what you are going to make, it tells you exactly when you need to make it" (ManCo employee);

"it's one of them kind of companies where if you're not in trouble you don't deal much with the managers" (BigBus employee).

This illustrates that the priority attached to particular aspects of job quality might be influenced by individuals' current work role; and also suggests that some job features have a greater impact in some industries or companies than in others. A further example of this relates to time factors. These were of low perceived importance to interviewees at ManCo. Interviewees here reported generally having sufficient time to complete their work, therefore the time factors were likely to be considered unimportant simply because they did not cause difficulties. At CleanCo, however, not having enough time to do the job was reported to adversely affect job quality. Although the difference was not statistically significant from that in other companies, it was apparent from the interviews that this was an issue of concern to many,

"It is harder than it used to be; they are putting more on us, but want to keep it to the same standard" (CleanCo employee);

"Sometimes there are bad things around so I don't have any choice, we are always dashing in this job. Over our capacity sometimes" (CleanCo employee).

The commitments which individuals had outside of work also influenced their perceptions of their jobs, and of the most important features. For example, working hours were identified as very important by interviewees at CleanCo, many of whom had chosen the job specifically because it fitted in with their family responsibilities for child care. However, working hours were of relatively low importance to those employed in bus and coach driving. This may reflect adaptation to the demands of variable shifts, or may indicate that those who value greater consistency in their working patterns self-select out of the industry,

"it's what the job entails, you know when you take it on, you know you will be working shifts” (BigBus driver); 
“it doesn't bother me, there are 24 hours in a day, it's the industry” (LittleCoach driver).

Although there were features which showed differences between companies and industries as shown above, there were other areas of job quality which showed variation at a more individual level. For example, in relation to features such as the desire for autonomy or promotion, or the perceived importance of relationships with colleagues, there were individuals in all organisations and job roles who identified these as being extremely important but many more who considered them to be of low significance (or, in the case of promotion, to be positively undesirable). Age or stage of life was given by some as an explanation for particular preferences, so that some declared themselves 'too old' to be concerned about learning new things, and others identified that income levels were of less concern now that their children had left home. Other variations appeared to be more influenced by personal styles or traits - so that some working in bus driving reported that they found it stressful to keep to fixed timetables amid the vagaries of traffic and passenger demands, whilst others accepted this as beyond their control and were undisturbed by it,

"It's how you make it yourself really. If you get stressed as a bus driver you get stressed all the time. If you take things as they come and don't panic and stress out you're alright then aren't you?" (LittleBus driver).

These influencing factors are widely recognised in the literature - for example the quote above reflects how individuals react differently to stressful situations (see for example Daniels et al 2004). Personality may also influence how individuals seek out or prioritise features such as status, meaningfulness or social support (Barrick, Mount, and Li, 2013). Therefore the finding that individuals vary in their job preferences is not novel. However, such variation does make it difficult to construct a universal model of job quality and potentially inappropriate to measure against one. Models of overall job quality rarely address this, measuring against a single set of principles, and failing to take into account the extent of differences between individuals and industries. This has the potential to result in a relatively narrow, paternalistic model of what a good job should look like.

\section{Job choice and compromise}

It was mentioned above that many of the employees working in CleanCo had chosen the job specifically because it fitted in with their family situation. Employees working in manufacturing and bus driving reported that they had chosen their jobs for reasons of expediency, practicality, or because of recommendations by family or friends. With the exception of some drivers who especially liked driving, relatively few interviewees had chosen their jobs because the content particularly appealed to them. In fact, many gave examples of other jobs which they considered preferable in content terms, but were not practical because they failed to satisfy key requirements such as providing sufficient pay or security,

"I would have worked on a farm all of my life if they paid a decent wage because farm work is the most fantastic job in the world but they pay absolutely appalling wages and I got married, I had children so you have to go and work and earn money" (ManCo employee); 
"In all fairness the only reason you would choose to do a cleaning job is the reason I took it on in the first place; because it fits in with the other life of being a housewife and a mother. So it was that reason and that reason alone...... it would be nice to have a job that you are really interested in doing" (CleanCo employee).

Hence, many job 'choices' were restricted and individuals compromised, particularly in terms of the actual content of a job. Nevertheless, job content reasons were often given as making the job good once interviewees were in post - examples of this were cleaners who found their work satisfying or enjoyed the relationships with the students whose rooms they cleaned, or bus drivers who derived satisfaction from building relationships with passengers. There was therefore a hierarchy in terms of job choice - the key requirements for each individual had to be satisfied, such as adequate pay, job security or family friendly working hours. Beyond this, there might be scope for the exact nature or content of a job to influence choice. This is not dissimilar to Maslow's model of human needs and motivation (Maslow 1943). This model has been criticised in the literature as empirical research has been unable to confirm some of its propositions (Wahba and Bridwell 1976). However, Peter Warr (2007b) describes as being 'plausible' its central tenet that 'higher order' needs become important once basic needs are satisfied. Hence Maslow considers that individuals will generally prioritise basic physiological needs such as food and water (which would equate to basic salary needs in the workplace context), then those relating to safety. Once these are reliably met, attention can be given to the 'higher order' needs such as love and belonging (workplace relationships) and 'self-actualisation' which may relate to the actual content and demands of a job.

In reality, there is likely to be variation in the extent to which individuals are able to satisfy these needs. Siegrist et al (2009) highlight that those from poorer socioeconomic backgrounds are commonly restricted in the jobs they can choose, due to limited skills or difficulties balancing work with other commitments. One consequence of this may be that they lower their expectations regarding job content, focussing only on the physiological and safety needs at the bottom of Maslow's hierarchy, and there is evidence that this occurs (Schokkaert, Van Ootegem and Verhofstadt 2011; Wallace, Pichler and Hayes 2007). It is unclear whether all those in such roles are merely tolerant of them, accepting that they do not have the luxury of a job which they enjoy and seeking a 'working situation which is as good as it can be all things considered' (Wadsworth, Chaplin and Smith 2010). This is certainly possible - it is apparent from the job satisfaction literature (e.g. Schokkaert, Van Ootegem and Verhofstadt 2011; Muñoz de Bustillo Llorente and Fernández Macías 2005) that those in relatively poor jobs often do not see them as being particularly onerous; this is likely to be influenced by their frame of reference, comparing a job to other jobs they have done or could expect to do. However, it is also possible that some are genuinely content, not because their expectations are low but because they enjoy what they do. In all the cohorts interviewed for example, there were some who found the work to be boring and repetitive, whilst others in the same role could see variation, interest and challenge which gave them satisfaction.

In other areas too, it is difficult to judge whether individuals' judgements of their work reflects preference or tolerance. For example, relationships with colleagues were identified as being less important by bus drivers than by those in other jobs - this could indicate that those in the job had chosen it for this reason, because the predominance of lone working suited them. However, it may also reflect acceptance and adjustment to the low level of contact, so that they no longer considered or admitted to it being important. Another example can be seen by comparing drivers from the three bus companies. Interviewees at LittleCoach 
considered hours, pay, and job security to be less important than did drivers at other companies. This may indicate self-selection into the job (which had lower pay than BigBus and less reliable hours than LittleBus and BigBus) as those who considered these features important would be unlikely to have chosen it. However it may also be that they had lowered their expectations to match the reality in order to minimise cognitive dissonance and distress (Muñoz de Bustillo Llorente and Fernández Macías 2005).

\section{The relationship between good work and health}

There is a prevailing view in parts of the literature that work is 'good' for health. Therefore, interviewees were asked an open question about what contributed to a job being 'good for health'. Many mentioned safety - an unsafe job could not be good for health, just as an unsafe job could not be a good job. Interviewees at CleanCo also discussed the impact of not having enough time to do their work, and how the high time pressures adversely affected their health. High time pressures prevented the work being good for their health as well as preventing it from being a good job.

Safety and time pressures therefore contributed to both whether a job was considered good and whether it was considered good for health. Other than this, interviewees identified different features as contributing to a job which was good and one which was good for health. For example, both the cleaners and the bus drivers recognised that a certain level of physical activity was good for health: some of the cleaners valuing the physical demands of their job, recognising that it contributed to their overall fitness; and most of the bus drivers regretting the sedentary nature of their work and the impact this had on their health,

"I think I am a lot fitter now than I was, doing this block, having to do running up and down the stairs, I am a lot fitter" (CleanCo employee);

"Not good for health because half the time you are sitting behind a wheel and most drivers are fat aren't they?” (LittleBus driver).

Some interviewees drew comparisons between their current job in this respect and ones they had worked in previously -for example manual jobs, which were recognised as being better for health in terms of fitness or weight control. However, this did not influence whether a particular job was considered to be good or not. In fact, interviewees often considered their jobs to be good whilst simultaneously acknowledging them to have an adverse effect on their health. For example, many bus drivers regretted the adverse impact of prolonged sitting (which they saw largely in terms of weight gain); but none suggested that this was a reason to seek a different job. Similarly, employees working in manufacturing commented on the adverse effect which their working hours had on their health, but saw this as being outweighed by the positive impact on family life of needing to work only a small number of (twelve hour) shifts. Whether or not a particular job was considered likely to be good for health, therefore, seemed to be of low importance when choosing a job or deciding whether a particular job was good. This implies a low expectation that employment could or should contribute positively to health. Such views may make individuals tolerant of, and resigned to, adverse health effects from their work and consequently unlikely to challenge poor working conditions. This is particularly problematic in the current economic and social climate as the pension age rises; individuals need to work for longer than they might have previously and 
therefore it is important that they remain in good health and particularly important that their work does not have a negative impact on their health.

A small number of individuals expressly commented that their work was good for their health, and that not being in work had deleterious effects,

"I get very depressed if I can't go to work, so yes I am better at work, I can't sit at home it would drive me nuts" (ManCo employee).

This view accords with the strong theme in the literature regarding the positive relationship between work and health (Waddell and Burton 2006; Warr 2007b; Sahlgren 2013). However, the more dominant view was either that work was not good for health or that goodness for health was neither a priority nor an expectation when choosing a job. Overcoming this perspective will be a challenge for governments who wish their populations to be tolerant of the need to work into older age, or seek to encourage those with long term health conditions to remain in the workplace.

\section{Modelling job quality}

It has been identified above that this study found core job features, important to (almost) all, and other features subject to more individual variation. It also showed job choice for the blue collar workers interviewed to be largely influenced by practical matters, with job content being a lower priority; and amongst these workers there was a low expectation that work is good for health. A job could be seen as good, even if it was not considered to be good for health.

Based on these findings, as well as the existing evidence from the literature regarding the adverse health effects of work, a preliminary model of job quality has been constructed and is shown in Figure 2. This summarises the requirements for a job to be considered 'good' by the individual doing a job. It also reflects the need for jobs to be good for health, or as a minimum not to be bad for health: this is clearly important at a societal level even if it is not identified as a key driver for some individuals.

\section{The features that contribute to job quality}

The model (Figure 2) reflects the wide variation between individuals in the job features which they consider to be important. It distinguishes between:

- the core features, which are important for almost all workers. In principle, better provision of each will contribute to improved job quality, both in terms of whether work is perceived as 'good' and its likely impact on health; and

- 'job fit' features which are important to some individuals but not others, or where individuals might have different preferences. The principle here is that each feature should be well matched to the individual doing the job. Thus for one individual providing more autonomy may make a job better; for another, providing less may be preferred. There is also variation in how important these features are, so that for some 
individuals, particular working hours might be a key limiting factor in job choice, whilst for others they are 'nice to have', a bonus rather than a necessity.

Many features included in the model show both core and job fit aspects. For example, many interviewees commented on the adverse impact of poor relationships with colleagues or managers. This is reflected as a core feature, a job cannot be good if relationships are poor. However, there was a range of views on how important it was to have close friends at work, and on the impact a manager might have on the experience of work more generally and these are therefore shown as aspects where job fit is important. Similarly, the feature 'time factors' was found to have a core element important for all employees, which related to work intensity and the impact this could have on health. This is supported by the literature where high demands have been associated with poor health (Karasek et al 1981). However, interviews also illustrated a variable, job fit element for this feature: this related more to the psychological impact on an individual of not being able to complete their work, exemplified in this study by the ways different bus drivers responded to running late against their timetables.

Thirteen job features are shown in the model. These are largely those listed in Figure 1which were drawn from the literature and which formed the basis of closed questions during interviews. However, Location (how close and accessible work was to home) is also included as this was identified in interviews as influencing job quality and job choice for many (particularly those without their own means of transport or those wanting to restrict the length of their working day to minimise conflict with family demands). Physical Activity is included as many (particularly bus drivers) commented on the impact that being sedentary at work had on their health. A different question structure may have highlighted slightly different features; for example, topics such as fairness and emotional demands are identified in the literature as being important contributors to job quality, but were not discussed explicitly in the interviews, arising instead under other themes such as job content or the role of managers. The feature job content in the model is shown as a single feature, which reflects the nature of a particular job and also encompasses the concepts 'interesting' and 'useful' which were discussed specifically in interviews. In addition, job quality for some may be influenced by job features which fall outside of the shortlist discussed and included in the model. Inevitably therefore the list of features used in the model will have limitations, as accuracy has been sacrificed in the pursuit of simplicity (Weick 1979; Warr 2007a). For similar reasons, the model does not explicitly address the complicated relationships between specific work features and health. For example, there is evidence in the literature that some individual job features have the capacity for a positive effect on health whilst others have capacity only for a negative effect (Wadsworth et al 2010) or that some features are curvilinear, having a positive effect at lower levels but becoming disadvantageous at higher levels (Warr 2007b; Karanika-Murray et al. 2009; Weick 1979).

\section{Influencers on how jobs are perceived}

The model identifies a number of influencers, the factors considered above such as personality, health and family role which were given by interviewees as reasons for prioritising particular job features. When choosing and judging jobs individuals are also influenced by their past experiences of work. Gender and age might also influence job 


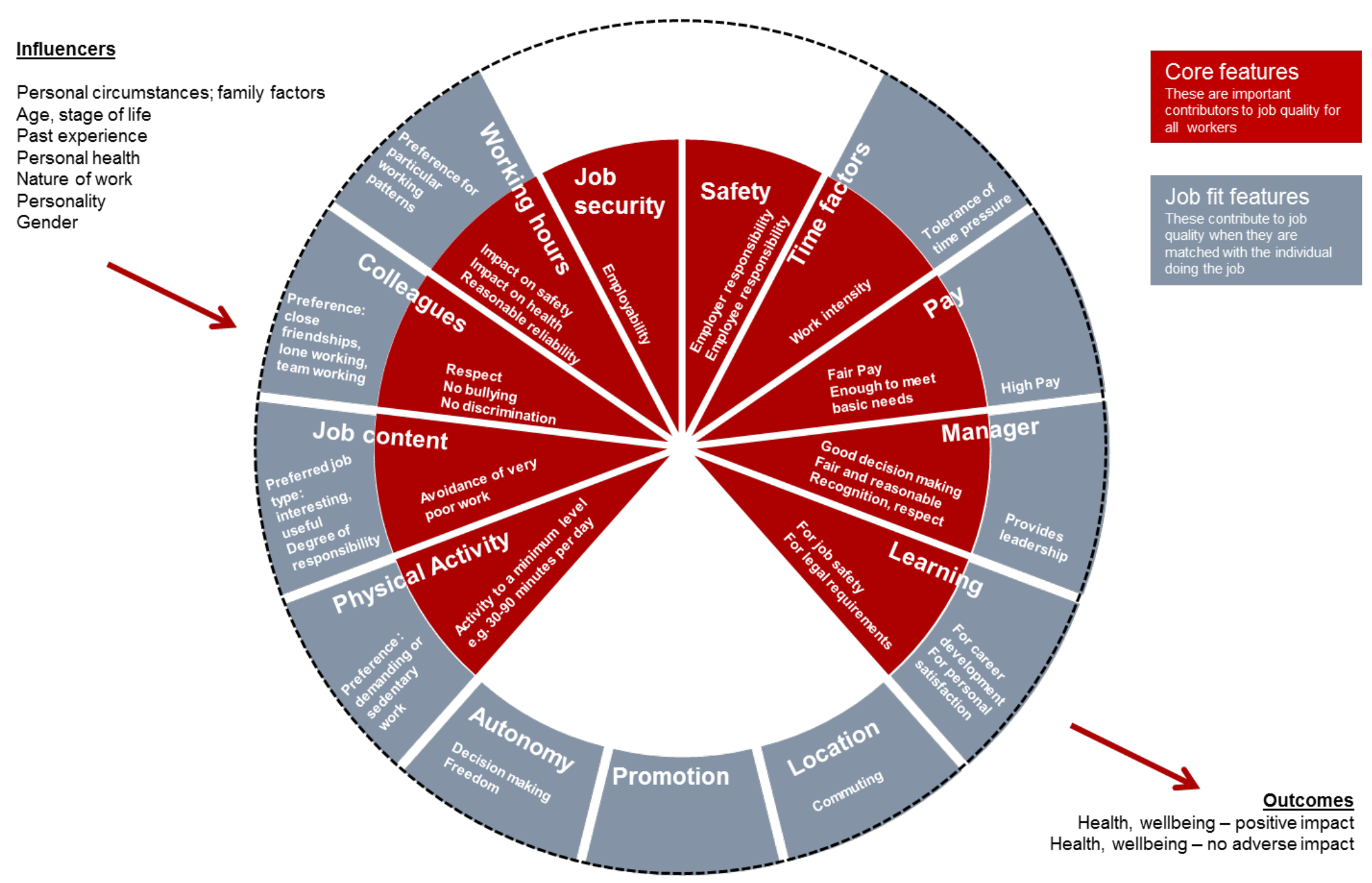

Figure 2 A theoretical model of job quality 
preferences, either directly through personality or experience effects or indirectly through impact on their family role and circumstances.

As a consequence of these many sources of variation, the 'perfect' job does not exist, only the best job for a particular individual in a particular situation. This makes it difficult to model job quality, but it is nevertheless important that jobs can be compared as a starting point to improve job quality.

\section{Developing and using the model}

To extend its applicability, the model needs further development using a larger and more varied study population. Interviewees in different job roles and industries (as well as those from different backgrounds or with different motivators or personalities) may identify different characteristics as contributing to job 'goodness' or job quality. Therefore the exact details of the core and job fit features would benefit from being evaluated against a larger data set. A further developed version of the model could then be used as a basis for a tool to measure and compare jobs, employers and industries. It was mentioned in the introduction to this paper that much assessment of job quality involves subjective measurement, for example through the use of survey tools. Such methods might be appropriate for some job features but would need to take account of individual variation. An example of one job quality measurement tool which does this is the DGB-Index from Germany (Mussman 2009; Jones et al. 2014a,b). This asks respondents how good different aspects of their work are (such as job security, work planning, support from colleagues), and follows up any negative responses by asking whether they are concerned about this. For example, a job may offer limited promotion prospects or may provide few opportunities for planning one's own work. Two employees may score the same job differently depending on whether these aspects of the work concern them. Thus there is potential for an employer to improve job quality by addressing specific aspects globally (such as increasing control over working hours or providing greater training opportunities); however, particularly where this is difficult to do, they can improve job quality by making greater efforts in matching jobs and individuals.

However, there are limitations to subjective measurement, not least the extent to which responses are influenced by individuals' expectations. Some of the features in the model, particularly those which have been identified as core, would lend themselves to more objective assessment. For example, a job which pays below the living wage (Davis et al. 2012) is worse in that respect than one which pays above it, regardless of the expectations of the incumbent. Similarly, adequate safety provision is essential (and legally mandated in the UK and many countries, including an obligation on employees to take good care of their own health and safety). It may therefore be more useful to assess it objectively - for example against legal standards, measured in terms of injury or ill-health records, or evaluated using audit or measures of safety climate. Further work would be required to identify the most appropriate measures to use in each case, in addition to the minimum 'level' of each required for a job to be identified as 'good'. The issue of physical activity in a job would be a particularly interesting area to address. There is strong evidence that sedentary behaviour and prolonged sitting are highly detrimental to health (Wilmot et al. 2012), and there is a need to design jobs which address this. Including a minimum activity standard in a job for it to be 'good', with commensurate benefits for society in terms of reduced ill-health, might be one way to promote more active ways of working. 
This last point highlights a key challenge when defining and measuring job quality - the risk of the process being overly paternalistic. Individuals may prefer jobs which are sedentary, regardless of the adverse impact on health, in the same way that people eat 'unhealthy' foods or consume excess alcohol. How far should a model go in specifying something as 'good' or even essential based on population based evidence? Past experiences, expectations and preferences will influence how an individual judges job quality both in overall terms and in terms of individual factors. The fact that their particular frame of reference may lead them to judge 'poorly' compared to population based evidence does not mean that these preferences should be discounted; particularly given that the health benefit for an individual of being happy in their work might in some cases outweigh the potential health impact of other aspects (such as being physically active). At the same time, this should not detract from the need to improve aspects of job quality universally where there is a strong evidence base to justify this. A combination of objective and subjective measurements and the distinction made here between core and job features is a pragmatic approach to finding this balance, but further work would be needed to decide exactly where to draw the boundaries.

\section{Closing remarks}

Ramazzini, writing about the adverse impacts of various jobs on the health of those who did them observed that his treatise on the topic was 'something of a novelty'. In the 300 years since the publication of De Morbis Artificum we have amassed a significant amount of evidence to support his assertions that work can cause harm. There is also a body of evidence showing that work can have positive impacts on wellbeing. There are ethical, practical and financial justifications for driving forward the job quality agenda. Nevertheless, progress towards a coherent framework for job quality as a single entity has been slow, hampered by its complexity and the multitude of perspectives adopted in the academic and government literature (Burchell et al. 2013). The model presented here contributes to this discussion by offering a model which reconciles the existing evidence on key factors such as job security, physical activity and work intensity with the importance of personal variation and preference. With further development the model could be used to underpin measurement of job quality and comparisons between organisations and jobs. At the same time it extends the remit of ergonomics from its more traditional interest in job design and the adverse impact of poor quality work.

\section{References}

Bakker, A.B., van Veldhoven, M. and Xanthopoulou, D., 2010. Beyond the demand-control model: Thriving on high job demands and resources. Journal of Personnel Psychology, 9 (1), 3-16.

Barrick, M.R., Mount, M.K. and Li, N., 2013. The theory of purposeful work behavior: The role of personality, higher-order goals, and job characteristics. Academy of Management Review, 38 (1), 132-153.

Bao, S.S., Kapellusch, J.M., Merryweather, A.S., Thiese, M.S., Garg, A., Hegmann, K.T. and Silverstein, B.A., 2015. Relationships between job organisational factors, biomechanical and psychosocial exposures. Ergonomics, 1-16. 
Berthelsen, H., Hjalmers, K., Pejtersen, J.H. and Söderfeldt, B., 2010. Good Work for dentists - a qualitative analysis. Community Dentistry And Oral Epidemiology;, 38 (2), 159170.

Black, C., 2008. Working for a healthier tomorrow. The Stationary Office

Bonnet, F., Figueiredo, J.B. and Standing, G., 2003. A family of decent work indexes. International Labour Review, 142 (2), 213-238.

Braun, V. and Clarke, V., 2006. Using thematic analysis in psychology. Qualitative Research in Psychology, 3 (2), 77-101.

Burchell, B., Sehnbruch, K., Piasna, A. and Agloni, N., 2013. The quality of employment and decent work: definitions, methodologies, and ongoing debates. Cambridge Journal of Economics.

Clark, Andrew E., 2005 Your money or your life: Changing job quality in OECD countries. British Journal of Industrial Relations 43.3: 377-400.

Coats, D. and Lekhi, R. 2008, , Good Work: Job Quality in a changing economy [Homepage of The Work Foundation], [Online]. Available from:

http://www.theworkfoundation.com/Assets/Docs/good_work_final3.pdf [Accessed October 7 2011].

Cooke, G.B., Donaghey, J. and Zeytinoglu, I.U., 2013. The nuanced nature of work quality: Evidence from rural Newfoundland and Ireland. Human Relations, 66 (4), 503-527.

Daniels, K., Jones, D., Fergusson, E., Perryman, S. and Rick, J. 2004, , Cognitive factors' influence on the expression and reporting of work-related stress :RR170 [Homepage of Health and Safety Executive], [Online]. Available from: http://www.hse.gov.uk/research/rrpdf/rr170.pdf [Accessed March 11 2011].

Davis, A., Hirsch, D., Smith, N., Beckhelling, J. and Padley, M., 2012. A Minimum income standard for the UK in 2012. Keeping up in hard times. York: Joseph Rowntree Foundation.

Department for Work and Pensions / Department of Health 2008. Improving Health and Work: Changing Lives - the government's response to Dame Carol Black's review of the health of Britain's working-age population [Homepage of TSO], [Online]. Available from: http://www.dwp.gov.uk/docs/hwwb-improving-health-and-work-changing-lives.pdf [Accessed July 29 2011].

Doef, M.v.d. and Maes, S., 1999. The Job Demand-Control (-Support) Model and psychological well-being: a review of 20 years of empirical research. Work \& Stress, 13 (2), 87-114.

Dul, J., Bruder, R., Buckle, P., Carayon, P., Falzon, P., Marras, W.S., Wilson, J.R. and van, d.D., 2012. A strategy for human factors/ergonomics: developing the discipline and profession. Ergonomics, 55 (4), 377-395. 
Edwards, J.R. and Cooper, C.L., 1990. The person-environment fit approach to stress: Recurring problems and some suggested solutions. Journal of Organizational Behavior, 11 (4), 293-307.

Gallie, D., 2013. Direct participation and the quality of work. Human Relations, 66 (4), 453473.

Grzywacz, J.G. and Dooley, D., 2003. “Good jobs” to “bad jobs”: replicated evidence of an employment continuum from two large surveys. Social science \& medicine, 56 (8), 17491760 .

Holman, D., Clegg, C. and Waterson, P., 2002. Navigating the territory of job design. Applied Ergonomics, 33 (3), 197-205.

HSE, 1974. Health and Safety at Work etc. Act.

ILO, 2013. The prevention of occupational diseases [Homepage of International Labor Organization], [Online]. Available from: http://www.ilo.org/wcmsp5/groups/public/--ed_protect/---protrav/---safework/documents/publication/wcms_208226.pdf [Accessed August 23 2013].

ILO, 2006. Decent Work: a Global Concept. World of work, 57, 4.

Jettinghoff, K. and Houtman, I. 2009, 18 February-last update, A sector perspective on working conditions [Homepage of Eurofound], [Online]. Available from: http://www.eurofound.europa.eu/pubdocs/2008/14/en/1/ef0814en.pdf [Accessed August 25 2011].

Johansson, J. and Abrahamsson, L., 2009. The Good Work - A Swedish Trade Union Vision in the Shadow of Lean Production. Applied Ergonomics, 40 (4), 775-780.

Johnson, J.V. and Hall, E.M., 1988. Job Strain, Work Place Social Support, and Cardiovascular Disease: A Cross-Sectional Study of a Random Sample of the Swedish Working Population. American Journal of Public Health, 78 (10), 1336-1342.

Jones, W., Haslam, R. and Haslam, C., 2014a. Measuring job quality: A study with bus drivers. Applied Ergonomics, 45 (6), 1641-1648.

Jones, W., 2014b. What is a good job? Modelling, measuring and improving job quality. Unpublished thesis (PhD). Loughborough University.

Kalleberg, A.L., 2008. The Mismatched Worker: When People Don't Fit Their Jobs. Academy of Management Perspectives, 22 (1), 24-40.

Karanika-Murray, M., Antoniou, A.S., Michaelides, G. and Cox, T., 2009. Expanding the risk assessment methodology for work-related health: A technique for incorporating multivariate curvilinear effects. Work \& Stress, 23 (2), 99-119. 
Karasek, R., 1979. Job Demands, Job Decision Latitude, and Mental Strain: Implications for Job Redesign. Administrative Science Quarterly, 24 (2), 285-308.

Karasek, R., Baker, D., Marxer, F., Ahlbom, A. and Theorell, T., 1981. Job Decision Latitude, Job Demands, and Cardiovascular Disease: A Prospective Study of Swedish Men. American Journal of Public Health, 71 (7), 694-705.

Leider, P.C., Boschman, J.S., Frings-Dresen, M.H. and van der Molen, Henk F, 2015. Effects of job rotation on musculoskeletal complaints and related work exposures: a systematic literature review. Ergonomics, 58 (1), 18-32.

Leschke, J., Watt, A. and Finn, M., 2008. Putting a number on job quality? Constructing a European Job Quality Index [Homepage of European Trade Union Institute], [Online]. Available from: http://www.etui.org/Publications2/Working-Papers/Job-quality-in-Europe [Accessed July 29 2011].

Luger, T., Bosch, T., Veeger, D. and de Looze, M., 2014. The influence of task variation on manifestation of fatigue is ambiguous-a literature review. Ergonomics, 57 (2), 162-174.

Maslow, A.H., 1943. A theory of human motivation. Psychological review, 50 (4), 370-396.

Michenthaler, G. 2006. “The Austrian Work Climate Index”, paper presented at the European Working Conditions Seminar on Job Satisfaction, November 9-10, Helsinki. Available from: http://www.eurofound.europa.eu/docs/events/seminarhelsinki2006/michenthaler091106.pdf.

Muñoz de Bustillo Llorente, R. and Fernández Macías, E., 2005. Job satisfaction as an indicator of the quality of work. Journal of Socio-economics, 34 (5), 656-673.

Muñoz de Bustillo, R., Fernández-Macías, E., Antón, J. and Esteve, F., 2011a. Measuring more than money Cheltenham UK: Edward Elgar.

Muñoz de Bustillo, R., Fernández-Macías, E., Esteve, F. and Antón, J., 2011b. E pluribus unum? A critical survey of job quality indicators. Socio-Economic Review, 9 (3), 447-475.

Mussman, F. 2009. The German “Good-Work” Index (DGB-Index Gute Arbeit). [Homepage of The Observatoire social européen (OSE)], [Online]. Available from:

http://www.ose.be/conf_ETUI2009/slides/DGB-

Index_ETUI_Gute_Arbeit.pdf;http://www.ose.be/conf_ETUI2009/slides/DGB-

Index_abstract.pdf; [Accessed June 20 2013].

Ramazzini, B., 1964. Diseases of workers ; translated from the Latin text, De morbis artificum of 1713, by W.C. Wright New York; London: Hafner.

Ritter, J.A. and Anker, R., 2002. Good jobs, bad jobs: Workers' evaluations in five countries. International Labour Review, 141 (4), 331.

Rose, M., 2003. Good Deal, Bad Deal? Job Satisfaction in Occupations. Work, Employment \& Society, 17 (3), 503-530. 
Sahlgren, G., 2013. Work Longer, Live Healthier: The relationship between economic activity, health and government policy. IEA discussion paper No 46.

Schokkaert, E., Van Ootegem, L. and Verhofstadt, E., 2011. Preferences and subjective satisfaction: measuring well-being on the job for policy evaluation. CESifo Economic Studies, 57 (4), 683-714.

Schumacher, E., 1979. Good Work London: Cape.

Sennett, R., 2008. The Craftsman London: Penguin Books.

Siegrist, J., 1996. Adverse health effects of high-effort/low-reward conditions. Journal of occupational health psychology, 1 (1), 27-41.

Siegrist, J., Benach, J., McKnight, A., Goldblatt, P. and Muntaner, C., 2009. Employment Arrangements, Work Conditions and Health Inequalities: Report on New Evidence on Health Inequality Reduction, Produced by Task Group 2 for the Strategic Review of Health Inequalities post 2010.

Singleton, W. (1972). Introduction to ergonomics. Geneva: World Health Organization.

Straker, L. and Mathiassen, S.E., 2009. Increased physical work loads in modern work - a necessity for better health and performance? Ergonomics, 52 (10), 1215.

Tangian, A., 2009. Decent work: indexing European working conditions and imposing workplace tax [Homepage of Sage on behalf of etui], [Online]. Available from: http://trs.sagepub.com/content/15/3-4/527 [Accessed July 29 2011].

Waddell, G. and Burton, A.K., 2006. Is work good for your health and wellbeing? London: The Stationary Office.

Wadsworth, E.J.K., Chaplin, K.S. and Smith, A.P., 2010. The work environment, stress and well-being. Occupational Medicine, 60 (8), 635-639.

Wahba, M.A. and Bridwell, L.G., 1976. Maslow reconsidered: A review of research on the need hierarchy theory. Organizational behavior and human performance, 15 (2), 212-240.

Wallace, C., Pichler, F. and Hayes, B.C., 2007. First European Quality of Life Survey: Quality of work and life satisfaction. Dublin :European Foundation for the Improvement of Living and Working Conditions.

Warr, P.B., 2007a. Searching for happiness at work. The Psychologist, 20, 726-729.

Warr, P.B., 2007b. Work, happiness, and unhappiness Mahwah, N.J. ; London: Lawrence Erlbaum Associates.

Waterson, P. 2011. World War II and other historical influences on the formation of the Ergonomics Research Society. Ergonomics, 54(12), 1111-1129. 
Weick, K.E., 1979. The social psychology of organising New York: McGraw-Hill.

WHO, 2010. Healthy Workplaces: a model for action. Geneva: World Health Organization.

Wilmot, E.G., Edwardson, C.L., Achana, F.A., Davies, M.J., Gorely, T., Gray, L.J., Khunti, K., Yates, T. and Biddle, S.J., 2012. Sedentary time in adults and the association with diabetes, cardiovascular disease and death: systematic review and meta-analysis.

Diabetologia, 55 (11), 2895-2905. 